\title{
Valoração contingente do parque Tia Nair (Brasil): comparação das técnicas Open-Ended e Bidding Games
}

\section{Contingent valuation of Tia Nair Park (Brazil): Comparison of open-ended and bidding- game techniques}

\author{
FABIANA LOEBLEIN* \\ Maria Daniele de Jesus-Teixeira**
}

\begin{abstract}
The present study aims to estimate and compare the economic value of Tia Nair Park (Cuiaba-Brazil). To do this, the contingent valuation method was applied through two techniques: open-ended and referendum with bidding games. The average value obtained was $R \$ 2,900,000$ against a willingness to pay of $R \$ 8.30$ and a population of 30,000 visitors. Different results were observed for the two techniques, with open-ended presenting more challenges for application, as well as overestimating the value found.
\end{abstract}

Keywords: Economic valuation, urban park, contingent valuation method.

\section{Resumo}

A presente pesquisa teve como objetivo estimar e comparar o valor econômico do parque Tia Nair (Cuiabá-Brasil). Para tal, aplicou-se o Método de Valoração Contingente através de duas Técnicas: Open-Ended e Referendum com Bidding Games. O valor médio obtido foi de R $\$ 2,900,000$ diante de uma disposição a pagar de R \$ 8.30 e uma populaçáo de 30,000 visitantes. Observou-se resultados diferentes para as duas técnicas sendo que a Open-Ended apresentou mais desafios para aplicação, assim como superestimou o valor encontrado.

Palavras-chave: valoração econômica; parque urbano; método de valoração contingente.

*Secretaria de Estado de Educação do Estado do Mato Grosso, correo-e: fabloeblein@gmail.com

**Universidade de Brasília e Universidade Federal de Mato Grosso, correo-e: mdani2827@gmail. 


\section{Introduçáo}

Os parques urbanos apresentam inúmeras funçôes, dentre elas, minimizar a degeneração da qualidade de vida urbana e ambiental. Um ambiente natural e agradável desses espaços oferece minimização dos problemas das cidades e traz benefícios para seus habitantes. $\mathrm{O}$ parque urbano pode ser compreendido como um espaço público com extensões bem significativas, diferente de praças, com áreas de arborização e equipamentos destinados à recreação e atividades físicas (Grena-Kliass, 1993). Além dos problemas ambientais urbanos, os parques também amenizam as tensóes sociais, pois proporcionam um espaço de aproximação do ser humano com a natureza (Dias-Ferreira, 2005).

No século XIX ocorreu uma vertiginosa expansão neste tipo de parque, que tiveram novas funçôes introduzidas, tais como práticas esportivas, culturais e preservação de recursos naturais, adequando áreas verdes aos espaços das cidades. Possibilitando no século XX uma melhoria na qualidade de vida da população, renovando as paisagens dos meios urbanos. No Brasil ao longo da década de 80, os Parques Urbanos passaram por grandes transformaçóes, como processo de valorização e preservação de sua vegetação, criando espaços para contemplação (Alencar-Maymone, 2009).

O parque urbano nasceu sob a concepção de dotar as cidades de espaços adequados para atender a nova demanda social: o lazer e o tempo do ócio, contrapondo-se ao ambiente urbano de vida agitada. A criação dos espaços verdes destinava-se especialmente à promoção da qualidade de vida urbana no bem-estar das pessoas (Maciel da Silva, 2003). Neste sentido, a criação de parques urbanos, tem como objetivo minimizar a degeneraçáo da qualidade de vida urbana e ambiental, gerados pelos processos de degradação, através da criação e manutenção favoráveis ao conforto urbano, saúde, bem-estar, vida biológica urbana, além de oferecer um local de encontros para as práticas de esportes, lazer, recreação, contemplação, entre outras.

Durante a história urbana de Cuiabá, é notória a falta de praças e parques frente ao crescimento de construçôes e à diminuição das áreas verdes. Estes lugares representam espaços simbolicamente saudáveis e higiênicos, e devido à superlotação dos parques da cidade, de pessoas em busca de bem-estar social, físico e psicológico, é notório o benefício que este tipo de ambiente traz. Quando o espaço público está degradado, provoca uma rejeição imediata. Segundo, Rodríguez-Alomá (2013) se renovados geram automaticamente "externalidades positivas", isto é, sinergias que atraem pessoas, recursos e inversão de valores. Para Lerner (2010: 13) "é fundamental que uma boa acupuntura urbana promova a 
manutenção ou resgate da identidade cultural de um local ou de uma comunidade [...]".

Nota-se imensa importância e contribuição dos parques urbanos para o bem-estar e qualidade de vida da população. No entanto, diante do processo de crescimento acelerado das cidades, muitas vezes são priorizados interesses econômicos particulares em detrimento de questôes ambientais e estruturais para populaçáo por não saber ao certo os custos e benefícios de determinados investimentos. Nesta perspectiva, o objeto deste estudo consiste em estimar um valor econômico do parque Tia Nair (Cuiabá- Brasil) sob a concepção da população que o frequenta. Para tal, utiliza-se do Método de Valoração Contingente (MVC), por meio de duas técnicas de abordagem: Open-ended e Referendum com Bidding Games.

O método consiste na aplicação de questionários para uma determinada amostra da população, pergunta-se as pessoas a disposição a pagar para melhorar ou conservar um determinado espaço a ser pesquisado ou ainda pode-se perguntar sobre a sua disposição a receber algum pagamento pela utilização de um determinado recurso ambiental. Os aspectos levados em consideração na pesquisa abrangem o perfil do entrevistado e sua renda, o lazer e bem-estar; o grau de instrução; a consciência ambiental, entre outras. Sua aplicação envolve técnicas de modelagem que possibilitam boas previsóes a partir de dados dos entrevistados.

A relevância deste estudo consiste principalmente na mensuração econômica do parque Tia Nair por meio da análise de dados primários nunca realizada anteriormente no espaço em questão. Essa mensuração leva em consideração a alteração de bem-estar advinda dos benefícios que o espaço como o parque urbano pode oferecer. A mensuração da magnitude desses benefícios é determinante para justificar políticas e investimentos culturais. Segundo, Zwilling-Stampe et al. (2008), como muitos bens e atividades culturais são gratuitos, faz-se necessária a utilização de um método alternativo para ser alcançado um valor de mercado que expresse em quanto as pessoas valoram esses bens e atividades.

Salienta-se que a pesquisa apresenta relevância também na literatura sobre os métodos de valoração quando possibilita a comparação de resultados, advindas de duas formas de abordagem Open-Endede Referendum com Bidding Games, utilizadas concomitantemente para um mesmo local e utilizando-se de amostras semelhantes e aleatórias.

Para Sachs (2008: 60) "é necessária uma combinação viável entre economia e ecologia, pois as ciências naturais podem descrever o que é preciso para um mundo sustentável, mas compete às ciências sociais a articulação das estratégias de transição rumo a este caminho". 


\section{Caracterizaçáo do parque Tia Nair}

O parque municipal "Tia Nair", que está localizado no município de Cuiabá capital do estado de Mato Grosso, o único parque da cidade com funcionamento noturno. Conforme a administração do parque recebe-se em média 7000 visitantes por semana. Nota-se que, principalmente à noite e aos finais de semana, é grande o número de visitação para as mais diversas finalidades.

Nair Cunha Monteiro "Tia Nair" era uma mulher muito importante na sociedade cuiabana, ela se destacou pelo seu espírito empreendedor, muito além de sua época. Foi uma grande educadora com foco principalmente na educação social familiar, estava sempre preocupada com as questóes sociais das classes mais humildes e sempre estava à frente das decisóes mais importantes da família, como a doação de 60 hectares de sua fazenda para a construção da Universidade Federal de Mato Grosso, pois tinha a visão que uma capital não poderia se desenvolver sem possuir uma universidade. No ano de 1977, Nair juntamente com seu esposo resolveram vender a fazenda, para seu sobrinho que era empresário do ramo da construção civil. Nair fez seu sobrinho prometer que iria realizar naquela área investimentos para poder desenvolver a cidade de Cuiabá. Promessa essa que se cumpriu, pois foi realizado naquela época algo que nunca havia sido feito em Cuiabá. Foi criado na região onde se encontra o parque, o condomínio Alphaville I e II, entre outros condomínios todos com infraestrutura completa.

\section{Fotografia 1 \\ Vista panorâmica noturna do parque Tia Nair}

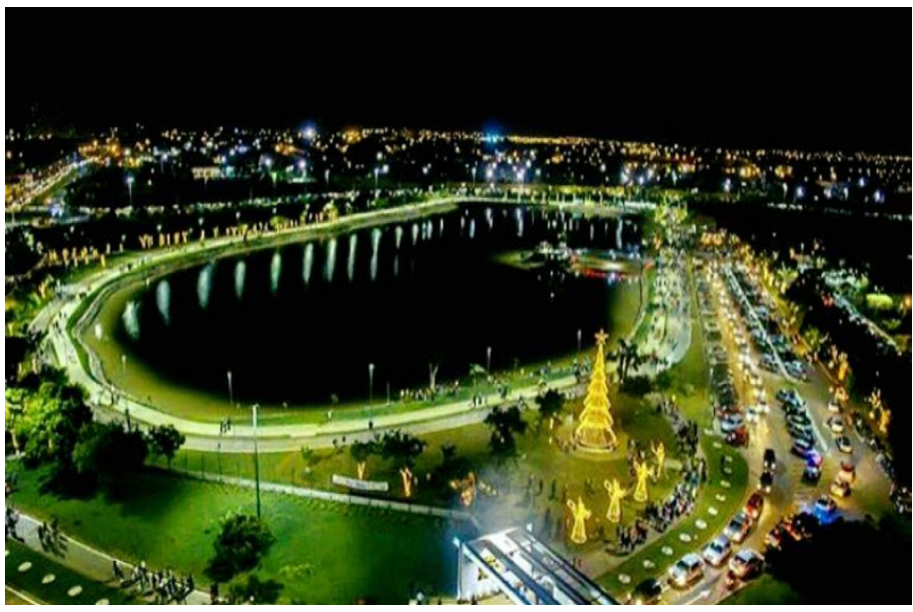

Fotografia: Prefeitura de Cuiabá (2016). 
O parque foi entregue a população em 15 de dezembro do ano de 2007, e hoje leva o nome de Parque Nair Cunha Monteiro "Tia Nair" devido a uma exigência de seu sobrinho e empresário, como forma de homenagear sua tia e madrinha. É o primeiro parque com funcionamento noturno em Cuiabá, possui segurança para que as pessoas possam aproveitar para praticar esportes, se divertir, relaxar e descansar. A fotografia 1 mostra a vista panorâmica noturna do parque.

O parque passou por uma reforma no ano de 2015 e teve sua área total ampliada em $43 \%$, passando a ter 20 hectares, e o local ganhou pistas de caminhada e ciclismo. A lagoa que está dentro do parque possui uma ilha, uma cascata de três metros de altura, pedalinho e tirolesa. Existe também uma academia coberta, parquinho infantil e 400 vagas de estacionamento. O parque ganhou o espaço cultural "Memorial dos Bandeirantes”, que abriga exposições contando a história de fundação de Cuiabá. Há ainda a construção de um restaurante, cuja administração será licitada para que uma empresa assuma a concessão.

\section{Metodologia}

O Método de Valoração Contingente (MVC) foi utilizado, pois segundo, Zwilling-Stampe et al. (2008) e Seroa da Motta (1997) busca, por meio de entrevistas, estimar valores de bens públicos para os quais não haja mercado, construindo assim mercados hipotéticos. Comumente utilizado para avaliar os impactos ambientais e fazer estimativas da disposição a pagar (DAP) para usufruir determinado bem ou participar de determinada atividade. Foram aplicados dois modelos de questionários com técnicas diferentes Open-ended e referendum com Bidding Games, para obtenção de valores comparativos da disposição a pagar (DAP) quando as questóes são abertas ou negociáveis.

O Método de Valoração Contingente busca através da construção de um mercado hipotético com perguntas diretas, o valor que as pessoas atribuem às mudanças de bem-estar que produzem modificaçóes nas condiçóes de oferta de um bem ambiental público. Segundo, Villalba (2004) a valoração obtida depende da opinião das pessoas a partir da informação recebida. Determinar o valor econômico de um recurso ambiental é estimar o valor monetário deste em relação aos outros bens e serviços disponíveis na economia (Seroa da Motta, 1997).

Sendo assim, procura-se criar cenários cujas características sejam as mais reais possíveis, de modo que as preferências reveladas nas pesquisas reflitam nas decisóes que os agentes públicos tomariam de fato se caso existisse um mercado para o bem ambiental descrito no cenário hipotético. 
Segundo a teoria econômica, as preferências dos entrevistados devem ser expressas em valores monetários. Esses valores são obtidos através das informaçóes adquiridas nas respostas dos entrevistados sobre quanto estariam dispostos a pagar (DAP) para garantir a melhoria de bem-estar, ou quanto estariam dispostos a aceitar em compensação (DAC) para suportar uma perda de bem-estar.

A grande vantagem do MVC, em relação a qualquer outro método de valoração, é que ele pode ser aplicado em um espectro de bens mais amplos, exemplo a pesquisa de Zwilling-Stampe et al. (2008) que estimou o valor da Feira do Livro, assim como Se-Young e Won-Seok (2017) que estimaram o valor do Jidong Mural Art Alley. A grande crítica, entretanto, ao MCV é a sua limitação em captar valores ambientais que indivíduos não entendem, ou mesmo desconhecem. Enquanto algumas partes do ecossistema podem não ser percebidas como geradoras de valor, elas podem ter condiçóes necessárias para a existência de outras funçóes que geram usos percebidos pelo indivíduo (Seroa da Motta, 1997).

A valoração contingente está vulnerável a vieses de comportamento na pesquisa quando não se toma os devidos cuidados na construção de questionário, na análise dos dados e no momento da pesquisa. Esses vieses aparecem desde o momento em que se passa a criar o cenário a ser pesquisado, na elaboração do questionário, na realização das entrevistas, levantamento dos dados e até mesmo na apresentação dos resultados (Gomes-Paixão, 2011). Segundo, Myers et al. (2017), deve-se ter atenção também quanto à frequência do pagamento, pois estudos mostram pouca sensibilidade quando comparado o pagamento único a outros frequentes, o que também pode gerar viés na pesquisa.

Como o MVC trabalha com dados primários, deve-se levar em consideração a forma de aliciação assim como atendimento às normas éticas de pesquisa. Conforme Conselho Nacional de Saúde por meio da Comissão Nacional de Ética na Pesquisa (Conep), na Resolução 510/16 que dispóes sobre as normas aplicáveis a pesquisas em Ciências Humanas e Sociais cujos procedimentos metodológicos envolvam a utilização de dados diretamente obtidos, no Art. 1 da Resoluçẫo CNS 510/2016 afirma: "Não serão registradas nem avaliadas pelo sistema CEP/CONEP: I pesquisa de opinião pública com participantes não identificados".

\subsection{Coleta de dados}

Para realizar a estimativa da DAP do parque, foram realizadas 273 entrevistas. Foi aplicada uma pesquisa piloto com 10 questionários aos visitantes do Parque Tia Nair para avaliar a clareza e o nível de compreensão dos entrevistados quanto aos questionários. Constatou-se a necessidade 
de fazer adequações em duas questóes já pré-definidas no questionário. Introduziu-se na questão dezenove a opção "frequenta pouco" e na questão vinte "não soube informar". Os dados são primários, coletados em campo por três alunas do curso de especialização em Sustentabilidade, as quais possuíam conhecimento sobre o método de valoração. $\mathrm{Na}$ aplicaçáo do questionário gastou-se em média de cinco a dez minutos para se concluir cada entrevista.

A forma utilizada para a amostragem foi casual-aleatório, somente com os frequentadores do parque. A aplicação ocorreu nos meses de setembro a novembro de 2016, alguns dias durante a semana no período noturno e aos finais de semana e feriados no período vespertino e noturno. A parte inicial do questionário versa sobre os aspectos socioeconômicos dos entrevistados, meio de transporte, objetivo da visita, quanto tempo de duração de sua visita, com que frequência visita o parque, quais aspectos determinantes para sua visita.

$\mathrm{Na}$ aplicação do questionário da técnica Open-ended questionava-se se o entrevistado estaria disposto a pagar para possibilitar melhorarias e a conservaçáo do parque e no caso de sim qual valor ele pagaria e quem deveria administrar esse recurso. Para os entrevistados do questionário da técnica Referendum com Bidding Games perguntava-se se ele estaria disposto a pagar o valor de $\mathrm{R} \$ 4.00$ para possibilitar melhorias e conservação do parque, no caso de resposta positiva valores superiores eram oferecidos. Se a resposta fosse negativa, lances menores eram oferecidos. Para ambos, no caso de a resposta ser negativa o entrevistado deveria expressar o motivo.

Para determinar os lances oferecidos aos entrevistados pela técnica Referendum com Bidding Games, utilizou-se de pesquisa bibliográfica, buscando artigos com objetivos e lugares semelhantes, assim como aplicaçáo de uma pesquisa piloto com 10 questionários. Nesta perspectiva, calculou-se um valor mediano, para que a DAP inicial não tenha influência sobre a DAP final. Para a técnica no formato Open-ended não houve determinação dos lances, tendo em vista que são lances abertos, ou seja, o entrevistado pode escolher qualquer valor, sem determinação de um valor inicial.

\subsection{Tamanho da amostra}

O parque Tia Nair recebe em média 1000 pessoas por dia durante a semana, porém aos sábados e domingos esse número pode chegar a 3500 visitantes por dia. O Parque encontra-se aberto ao público diariamente das 5 horas da manhã até às 23 horas da noite e recebe maior quantidade 
de pessoas no período vespertino e noturno para as mais diversas finalidades de lazer e ou recreação.

Neste trabalho o tamanho da amostra foi estimado conforme metodologia proposta por Gil (2008: 97) para populaçóes finitas (abaixo de 100,000 observações), conforme descrita abaixo:

$$
n=\frac{\sigma^{2} p \cdot q \cdot N}{e^{2}(N-1)+\sigma^{2} p \cdot q}
$$

$n=$ Tamanho da amostra

$\sigma^{2}$ Nível de confiança escolhido, expresso em número de desvios-padrão

$p=$ Percentagem com a qual o fenômeno se verifica

$q=$ Percentagem complementar

$\mathrm{N}=$ Tamanho da população

$e^{2}=$ Erro máximo permitido

Para determinação do tamanho da amostra da pesquisa foi adotado dois desvios-padrão, trabalhando com nível de confiança de 95\% (Gil, 2008). Para a probabilidade de ocorrência do evento " $p$ ", adotou-se o valor máximo de $65 \%$ conforme trabalho de Silva et al. (2012), e, consequentemente, " $q$ " igual a $35 \%$. A população de visitantes é em média 30,000 pessoas por mês segundo administração do Parque, constituindo o valor de " $N$ ”. O erro máximo permitido será de $6 \%$ conforme proposto por Gil (2008: 96). A partir dos pressupostos descritos acima, verificou-se a necessidade de aplicar 260 questionários. No entanto, adicionaram-se 5\% sobre esse valor, totalizando 273 questionários. $\mathrm{O}$ valor adicionado visa minimizar possíveis perdas de questionários aplicados no parque.

Para aplicação das duas técnicas Open-ended e Referendum com Bidding Games a amostra foi dividida em duas partes: Amostra para Open-ended com 136 entrevistados aleatórios e aplicação do questionário tipo A (3 questionários não foram considerados por erros no preenchimento, totalizando 133 questionários válidos) e Amostra para Referendum com Bidding Games, com 137 entrevistados aleatórios e aplicação do questionário tipo B (com mais de uma questão sobre o valor do pagamento).

\subsection{Técnica Open-Ended}

A técnica Open-ended também é encontrada em alguns estudos com a denominação Lances Livres e constitui uma das técnicas diretas mais simples. Esta propóe captar o valor econômico do bem ou serviço ambiental valorado por meio de pergunta direta ao entrevistado, no caso, 
questiona o quanto ele está disposto a pagar pelo bem valorado. A resposta será um determinado valor $\mathrm{X}$, gerando uma variável continua com valores diferenciados. Conforme Seroa da Motta (1997) é possível calcular a Disposição a Pagar (DAP) ou Disposição a Aceitar (DAA) através da sua média.

As limitações desta técnica residem nas dificuldades de imaginar um valor justo, em se tratando de bens ambientais, porque não existir um valor econômico apropriado no mercado, resultando em respostas com valores variados. Se, neste caso, forem feitas várias perguntas, de um lado, facilita a opiniáo dos entrevistados, mas, por outro, pode induzir respostas tendenciosas (Hammack e Mallard-Brown, 1974).

Para o cálculo da Disposição à Pagar (DAP), utilizou-se a seguinte equação segundo Seroa da Motta (1997):

$$
D A P_{O E M}=\sum_{i=1}^{5}\left(D A P_{M i} * \frac{n i}{N}\right.
$$

Onde:

$D A P_{O E M}=$ Valor médio da disposição a pagar pela técnica Open-ended $n i=$ número de entrevistados de acordo com sua $D A P M$

$N=$ número de pessoas entrevistadas na técnica Open-ended.

$i=$ um dos 5 intervalos relativos as respostas quanto a $D A P$

Após o levantamento dos dados foi possível obter a valor médio encontrado da DAP, pode-se obter o valor do Parque extrapolando para o total de visitantes, representando assim, o valor médio dos benefícios atribuídos ao Parque.

\subsection{Técnica Referendum com Bidding Games}

Referendum é uma técnica do Método de Valoração Contingente e também é encontrada em alguns estudos como Referendo com Acompanhamento. De acordo com Seroa da Motta (1997) esta é a forma de indagação mais usada atualmente e é preferível em relação à aberta porque permite menor ocorrência de lances estratégicos dos entrevistados que procuram defender seus interesses ou beneficiam-se da provisão gratuita do bem.

No formato referendum com Bidding Games a pergunta é elaborada como forma a se obter do entrevistado um valor monetário que representa sua máxima DAP por meio de um jogo interativo de valores. Inicia-se com um valor mediano e, conforme a resposta, aumenta-se ou reduz-se o valor inicial. Essa técnica foi introduzida por Davis (1963).

Para a operacionalização desta técnica seguiu-se a seguinte metodologia. Oferecia-se um valor inicial predeterminado de $\mathrm{R} \$ 4.00$ para o en- 
trevistado, caso aceitasse, valores superiores eram oferecidos até atingir um valor máximo. Quando o entrevistado não aceitava o valor inicial, valores inferiores eram oferecidos. Logo, cada lance pode ser representado como valores dicotômicos (aceita, sim, 1 (um)), (rejeita, não, 0). Por fim, o número total da amostra foi de 520 observaçóes, o qual corresponde ao total dos lances oferecidos (varia de acordo com respondente, até encontrar o valor máximo que o indivíduo estaria disposto a pagar) multiplicando por (137) número de questionários válidos.

Cabe salientar que a variável latente DAP tem sua origem em variáveis binarias (podem assumir o valor de 0 (rejeita) ou 1 (aceita)). Dessa forma, esta variável pode ser formada pela diferença de utilidade que existe caso o evento de interesse ocorra, partindo da premissa que o resultado do processo de escolha binário é uma escolha individual.

Nesta pesquisa a formalização da técnica Referendum segue de acordo com Seroa da Motta (1997) e está de acordo com a segunda forma citada no parágrafo anterior. A aleatoriedade é tratada de forma diferenciada no método de Valoração Contingente, de forma que existam fatores não-observáveis e estocásticos que podem representar, por exemplo, variações nas estruturas de preferencias. A técnica Referendo consiste na hipótese do fato de os entrevistados conhecerem sua função de utilidade, mas existem termos não-observáveis que são desconhecidos pelo condutor da pesquisa. Pressupondo que seja o pagamento proposto por uma determina melhoria ambiental. Se a mesma for aceita, pode-se medir a variação de utilidade com o pagamento de $S$ e da utilidade sem o mesmo, é descrita pela equação1

$$
\Delta U=u\left(y-S, z_{1}\right)-u\left(y, z_{0}\right)+\eta>0
$$

Onde e representam, respectivamente, a qualidade ambiental final e inicial, a renda do indivíduo e uma variável aleatória com valor esperado zero. Normalizando os valores de $S$ em um, é possível obter-se a curva de demanda agregada $D$ para a variação ambiental $S$ em relação a função densidade probabilidade através da seguinte diferença:

$$
D(S)=1-F(S)
$$

Utilizou-se do software StataIC 12 para rodar os modelos econométricos, após análise destes, o preferível pelo ajustamento aos dados foi o Modelo Linear na Renda. Segundo, Haab e McConnell (2002), este método possui a característica de não utilizar a renda no cálculo dos parâmetros. Desta forma, a probabilidade de dizer sim ao pagamento é descrita pela equação 5 : 
$\operatorname{Pr}\left(\theta<\left(\alpha_{0}+\alpha_{1} \operatorname{var} 3+\alpha_{2} \operatorname{var} 5+\alpha_{3} \operatorname{var} 6+\alpha_{4} \operatorname{var} 7+\alpha_{5} \operatorname{var} 8-\beta t\right) / \sigma\right)$

Em que $t=$ valor apresentado com sinal negativo, var corresponde às variáveis utilizadas e $\alpha$ os coeficientes resultantes do modelo. Para o cálculo da DAP, segundo, Haab e McConnell (2002) utiliza-se da utilidade dos indivíduos levando em consideração a mudança do bem-estar, desta forma, para responder sim ao pagamento, a utilidade final deve estar no mesmo nível da utilidade inicial. Desta forma, para o modelo linear na renda, a equação para calcular a DAP média para a técnica Referendum com Bidding Games é:

$$
D \hat{A} P=\frac{\hat{\alpha} \bar{z}_{j}}{\hat{\beta}}
$$

Em que $\alpha$ representa os coeficientes estimados $\hat{\beta}$, coeficiente estimado para o valor apresentado, $z$ as médias das variáveis da amostra.

\section{Perfil socioeconômico dos usuários do parque Tia Nair}

Para estimar o valor econômico do parque Tia Nair, assim como analisar a população que o frequenta foram entrevistados 273 indivíduos. A maioria destes é residente em Cuiabá, do sexo feminino, possui ensino superior completo, trabalha em empresa privada, possui entre 25 a 31 anos, frequenta o parque pelo menos uma vez por mês, possui salário entre um e dois salários mínimos. No que diz respeito aos aspectos determinantes de visita ao Parque, os entrevistados consideraram fundamental a infraestrutura e segurança; em seguida a presença de vegetação e presença de animais e por fim proximidade da residência e atividades culturais.

Dos 273 entrevistados 76\% residem em Cuiabá e 16\% residem em Várzea Grande município vizinho a cidade de Cuiabá. Pode-se observar um valor significativo de visitantes de Várzea Grande, possivelmente devido à proximidade das duas cidades, assim como a carência de parques urbanos na própria cidade. Quanto à frequência dos frequentadores, nota-se que $8 \%$ é população flutuante, ou seja, são visitantes que estão de passagem por Cuiabá.

$\mathrm{Na}$ Tabela 1 os frequentadores são relacionados por faixa etária e gênero. Observa-se que 62\% são do gênero feminino e 38\% do gênero masculino, mostrando uma diferença considerável. Em relação a faixa etária obser- 
vou-se uma distribuição bem heterogênea, identificando que a faixa etária entre 25 a 31 anos é a mais expressiva, com $22 \%$ dos frequentadores. Baseada nas respostas dos frequentadores dessa faixa etária, a maior motivação para ir ao parque consiste na prática de esportes. Em segundo lugar a faixa etária de 32 a 38 anos representando $21 \%$ dos frequentadores, em terceiro lugar a faixa etária entre 18 a 24 representa $17 \%$.

\section{Tabela 1}

Frequentadores do parque Tia Nair por faixa etária e gênero

\begin{tabular}{lccc}
\hline Faixa Etária (em anos) & Frequentadores $\%$ & Masculino \% & Feminino \% \\
\hline 18 a 24 & 17 & 7 & 11 \\
25 a 31 & 22 & 8 & 14 \\
32 a 38 & 21 & 8 & 13 \\
39 a 45 & 14 & 6 & 8 \\
46 a 52 & 9 & 4 & 4 \\
53 a 59 & 9 & 2 & 6 \\
Mais que 60 & 8 & 3 & 5 \\
Total Geral & 100 & 38 & 62 \\
\hline
\end{tabular}

Fonte: elaboração dos autores (2016).

Com relação à ocupação principal, 30\% disseram ser empregados de empresa privada, $20 \%$ funcionários públicos, $11 \%$ empresários, $10 \%$ estudantes. Os menores percentuais foram registrados para aposentados e desempregados com $7 \%$, seguido por $6 \%$ de mulheres que afirmaram ser do lar.

$\mathrm{Na}$ tabela 2 os frequentadores são relacionados por nível de escolaridade. Observou-se que 33\% disseram possuir o ensino superior completo, seguido por $28 \%$ o ensino médio completo, e $12 \%$ disseram possuir algum tipo de pós-graduação. Conclui-se que a maior parte dos frequentadores do parque são de pessoas com alto nível de escolaridade, o que pode ser influência da localidade do parque, pois encontra-se próximo a um condomínio de classe alta.

Conforme os resultados apresentados no Atlas do Desenvolvimento Humano (2011) de Cuiabá, nos anos de 2000 e 2010, o percentual de escolaridade das pessoas com 25 anos de idade ou mais, que possuem curso superior completo, apresentou um significativo crescimento, registrando $11.9 \%$ e $19.9 \%$, respectivamente. Com relação à ocupação principal os maiores percentuais foram de $30 \%$ para empregados de empresa privada, $20 \%$ funcionários públicos e $11 \%$ empresários. Os menores 
Tabela 2

Nível de escolaridade dos frequentadores do Parque Tia Nair.

\begin{tabular}{lcc}
\hline \multicolumn{1}{c}{ Nivel de Ensino } & $\begin{array}{c}\text { Quantidade de } \\
\text { Frequentadores }\end{array}$ & (\%) \\
\hline Ens. Fundamental Incompleto & 12 & 4 \\
Ens. Fundamental Completo & 10 & 4 \\
Ens. Médio Incompleto & 12 & 4 \\
Ens. Médio Completo & 76 & 28 \\
Superior incompleto & 41 & 14 \\
Superior Completo & 90 & 33 \\
Pós-graduação & 32 & 12 \\
Total Geral & 273 & 100 \\
\hline
\end{tabular}

Fonte: elaboração dos autores (2016).

percentuais foram registrados para aposentados e desempregados com $7 \%$, seguido por $6 \%$ de mulheres que afirmaram ser do lar.

Com relação à frequência de visitação ao Parque, $24 \%$ dos entrevistados vão pelo menos uma vez por semana; $31 \%$ vão uma vez por mês; $23 \%$ afirmaram ser a primeira vez e apenas 3\% vão ao parque todos os dias. Em relação ao meio de transporte utilizado pelos frequentadores para ir até o parque, $85 \%$ utilizam o carro como o principal meio de transporte; $8 \%$ utilizam a motocicleta como meio de transporte; apenas 3\% vão caminhando; $2 \%$ utilizam ônibus e $0.4 \%$ utilizam bicicleta e taxi.

Diante da importância da renda de cada indivíduo para o valor que poderia pagar, questionou-se também sobre o salário. No período de realização da pesquisa, o salário mínimo vigente no Brasil era de $\mathrm{R} \$$ 880.00. Segundo a tabela $3.23 \%$ dos entrevistados possuem renda entre 1 e 2 salários mínimos ( $R \$ 880.00$ a $\mathrm{R} \$ 1760.00), 19 \%$ estão as pessoas com renda entre 3 (três) e 4 (quatro) salários mínimos ( $\mathrm{R} \$ 2640.00 \mathrm{a}$ $\mathrm{R} \$ 3520.00$ ), 20\% dos entrevistados alegaram náo possuir renda, por estar desempregado ou ser estudante. $\mathrm{O}$ maior percentual dos entrevistados recebia remuneração entre 1 (um) e 2 (dois) salários mínimos. Este valor é inferior ao divulgado pelo IBGE (2015) para o município de Cuiabá que teria como salário médio mensal dos trabalhadores formais de 3.8 salários mínimos, para Várzea Grande seria mais próximo, 2.3 salários mínimos. Outro ponto a considerar é a grande quantidade de desempregados o que reflete um momento econômico complicado na época da aplicação dos questionários. As técnicas aplicadas visam reduzir esse viés econômico. 


\section{Tabela 3}

Nível de renda mensal dos frequentadores do Parque Tia Nair

\begin{tabular}{lcc}
\hline \multicolumn{1}{c}{ Nivel de renda } & $\begin{array}{c}\text { Quantidade de } \\
\text { frequentadores }\end{array}$ & (\%) \\
\hline Sem renda fixa & 55 & 20 \\
Até R \$ 879.00 & 27 & 10 \\
R\$ 880.00 a R \$1.759.00 & 63 & 23 \\
R\$ 1,760.00 a R \$2,639.00 & 44 & 16 \\
R \$ 2,640.00 a R \$3,519.00 & 52 & 19 \\
Maior que 3,520.00 & 33 & 12 \\
Total Geral & 273 & 100 \\
\hline
\end{tabular}

Fonte: elaboração dos autores (2016).

Quando interrogados dos objetivos da visita ao Parque, a maioria (55\%) afirmou que vai ao parque para caminhar e passear; $24 \%$ vão para realizar passeio e recreação com crianças; $16 \%$ de entrevistado indicaram ir pela primeira vez ao parque para conhecer e $4.5 \%$ afirmaram ir ao parque para namorar/paquerar por ser um ambiente onde é possível ter contato com pessoas.

Quanto ao tempo de permanência no Parque, o maior percentual ficou para quem permanece cerca de duas horas com 45\%; seguida daqueles que permanecem cerca de uma hora com 37\%. Era comum ouvir dos frequentadores, que se sentiam táo confortáveis e seguros dentro do parque que muitas vezes nem percebiam o tempo passar.

No que diz respeito ao estado de conservação, pode-se observar que é grande o número de pessoas que consideram o estado de conservação "bom" com $73 \%$ dos frequentadores, $19 \%$ dos frequentadores consideram a conservação como "ótimo", e apenas $7 \%$ indicaram a conservação como "regular"; não ouve indicaçáo para o estado de conservação "ruim". Podemos considerar, que os frequentadores do parque Tia Nair estão satisfeitos com o estado de conservaçáo e manutenção do parque.

Em relação a percepção se o parque contribui para a educação ambiental dos frequentadores do parque Tia Nair, 86\% responderam "sim" para contribuição a educação ambiental da comunidade e apenas 16.54 $\%$ falaram que "não". De acordo com muitos frequentadores, o parque poderia incentivar a criação de açóes onde houvesse a participação da comunidade em relação a importância das questóes ambientais, bem como programas educativos sobre educação ambiental.

Pode-se afirmar que o parque possibilita a melhoria no nível de qualidade de vida da sociedade e que espaços como esse tem importância bem 
expressiva. Os 273 entrevistados acreditam que o Parque possibilita uma melhora significativa no nível de qualidade de vida da sociedade e acham importante a criação desses espaços. Diante do exposto, nota-se a importância da conservação e implantação de espaços como este para o bem-estar da população.

\section{Estimação da disposição a pagar (DAP): Técnica Open-Ended}

Nesta seção, será analisada a amostra 1 com 133 questionários (dos 136 questionários, 3 foram excluídos por conter erros) através da técnica Open-ended. Segundo, Abad (2002) a técnica Open-ended tem conduzido a um grande número de respostas "nulas" devido à dificuldade dos entrevistados em apresentar um valor que possa ser considerado como factível. Em função deste problema, outras técnicas têm sido preferidas, utilizando outras formas de questionamento que permitem ao usuário a escolha de um valor coerente.

Os resultados da pesquisa mostram que $53.38 \%$ dos frequentadores estariam dispostos a pagar um valor mensal para possibilitar melhorias, manutenção e conservação do parque Tia Nair. Considerando a metodologia adotada, a DAP média estimada para o público frequentador do Parque foi de R\$ 9.22 ao mês por pessoa, considerando o total dos frequentadores dispostos e não dispostos a pagar.

O valor estimado de $\mathrm{R} \$ 9.22$ ao mês é considerado elevado em relação a outros estudos que valoram parques por meio do MVC. Pode-se citar Cançado-Viana et al. (2006) que estimou uma DAP de 1,48 para melhorias e manutenção do Parque Ecológico e de Uso Múltiplo Olhos d'água. Outro estudo foi de Tafuri (2008) que estimou o valor de $\mathrm{R} \$ 5.50$ por ano por pessoa para preservaçáo ambiental do Parque Itacolomi em Minas Gerais.

Em diversos estudos de valoração contingente de parques e áreas verdes urbanas, que utilizaram a DAP, os percentuais de visitantes dispostos a pagar foram superiores ao encontrado nesse estudo. Onde pode-se citar a pesquisa feita por Lopes da Costa (2016) no Parque Mãe Bonifácia, onde o número de visitantes dispostos a pagar foi de $62 \%$. Cita-se também o estudo de Tafuri (2008) em que $70 \%$ aceitariam pagar. No entanto, diante do momento econômico e político ao qual a pesquisa foi feita, considera-se o percentual de 53.38\% satisfatório. Na pesquisa de Chen e Qi (2017) também obtiveram um número considerável de respostas de protesto e atribuíram ao uso gratuito do Parque Florestal analisado e além disso, o veículo de pagamento utilizado na pesquisa considerar uma taxa de entrada. 
A gráfico 1 descreve os valores informados pelos entrevistados que aceitariam pagar algum valor segundo a técnica Open-ended, assim como as frequências as quais estes valores foram mencionados.

\section{Gráfico 1}

\section{Histograma dos valores da disposiçáo a pagar pelos frequentadores do parque Tia Nair}

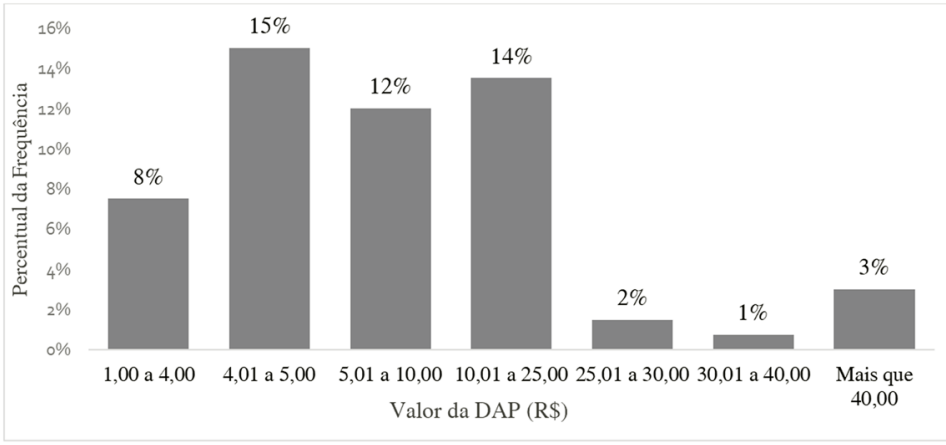

Fonte: elaboraçâo dos autores (2016).

Dos entrevistados que aceitariam pagar (53\%), foi questionado ainda sobre o valor que pagariam. Nota-se que os valores que apareceram com mais frequência foram de $\mathrm{R} \$ 4.01$ a $\mathrm{R} \$ 5.00$ com $15 \%$ seguido de $\mathrm{R} \$ 10.01$ a $\mathrm{R} \$ 25.00$ com $14 \%$ e $\mathrm{R} \$ 5.01$ a $\mathrm{R} \$ 10.00$ com $12 \%$ da preferência dos entrevistados dispostos a pagar. Os valores extremos tanto inferiores como superior foram citados em menor frequência, por exemplo: $\mathrm{R} \$ 1.00 \mathrm{e}$ $\mathrm{R} \$ 40.00$.

Considerando a DAP segundo a renda familiar, nota-se que os visitantes que tem maior disposiçáo a pagar pertencem à faixa de renda entre um e dois salários mínimos com $21 \%$; seguido pela faixa de renda de dois, três e quatro salários mínimos somando $40 \%$. É interessante observar que $25 \%$ dos frequentadores que não possuíam renda, aceitariam contribuir com algum valor. A menor disposição a pagar encontrada foi para faixa de renda familiar entre cinco e dez salários mínimos com $10 \%$.

Quando a DAP é relacionada com o nível educacional dos frequentadores podemos observar que os que possuem nível superior completo (29\%) estavam mais dispostos a contribuir, seguido pelos frequentadores de nível médio (28\%). Na pesquisa de Lopes da Costa (2016) também podemos observar essa preferencias dos frequentadores de nível superior completo com $58 \%$ das respostas.

Observa-se que $46.62 \%$ dos entrevistados não se dispuseram a contribuir com nenhum valor para proporcionar melhorias, manutenção e 
preservação do parque Tia Nair. A tabela 4 mostra uma descrição das justificativas para os valores nulos, verificando-se que as respostas que indicam o viés de protesto: $a$ ) a manutenção e preservação do governo e b) já pago muitos impostos destacam-se como principal fator explicativo para a não aceitação do pagamento.

\section{Tabela 4}

Motivos para o não pagamento dos frequentadores do parque Tia Nair

\begin{tabular}{lc}
\hline \multicolumn{1}{c}{ Motivo } & Quantidade de pessoas (\%) \\
\hline Competência do governo & 43.55 \\
Frequenta pouco & 4.84 \\
Já pago muito imposto & 20.97 \\
Motivos econômicos & 14.52 \\
Não acredito que terá uma manutenção melhor & 1.61 \\
Não tenho interesse & 4.84 \\
Não vejo necessidade & 8.06 \\
Total Geral & 100.00 \\
\hline
\end{tabular}

Fonte: elaboração dos autores (2016).

\section{Estimaçáo da disposição a pagar (DAP): Técnica Referendum com Bidding Games}

Nesta seção, a DAP máxima manifestada pelo entrevistado é analisada através da técnica Referendum com Bidding Games, ou seja, a pergunta é elaborada como forma a se obter do entrevistado um valor monetário que representa sua máxima DAP por meio de um jogo interativo de valores. Esse tipo de análise possibilita verificar as variáveis que influenciam a DAP máxima apresentada pelo indivíduo e, consequentemente, se os resultados obtidos correspondem ao esperado pela teoria econômica.

O lance inicial definido para aplicação desta técnica, conforme visto anteriormente, foi o valor de $\mathrm{R} \$ 4.00$, caso o entrevistado aceitasse, lance maiores eram oferecidos, caso não aceitasse lances menores eram oferecidos. Foram analisados 137 questionários que geraram 520 observaçóes de acordo aceitaçáo ou não do valor oferecido. Aproximadamente 55.61\% dos entrevistados aceitariam pagar para entrar no Parque, o que indica que o valor pode ser próximo ao estipulado. As variáveis escolhidas com possível influência sobre a DAP estão detalhadas na tabela 5 . 


\section{Tabela 5}

\section{Legenda das nomenclaturas das variáveis utilizadas no modelo}

\begin{tabular}{lll}
\hline Variável & \multicolumn{1}{c}{ Abreviação } & \multicolumn{1}{c}{ Descrição } \\
\hline Var1 & Depend & Variável dependente sim (1) e não (0) \\
Var2 & $\mathrm{t}$ & Valor apresentado sobre o qual respondeu sim ou não \\
Var3 & Idade & Idade \\
Var4 & Renda & Renda \\
Var5 & Sexo & Sexo: mulher $(0)$ homem (1) \\
Var6 & Escol. & Escolaridade \\
Var7 & TPerman. & Tempo de permanência em horas \\
Var8 & Freq. & Frequência \\
\hline
\end{tabular}

Fonte: elaboraçâo dos autores (2016).

Para estimação dos modelos de variável dependente binária (Probit e Logit) utilizou-se do software Stata 12.0. Após análise dos modelos de Utilidade marginal da renda variável, Utilidade Randômica com transformação Box-Cox da renda, Linear e Log-linear na renda, optou-se por utilizar o modelo Linear na Renda por regressão Probit (tabela 6) por ser preferível aos demais por meio do teste de razão de verossimilhança (LRT) e teste de melhor previsibilidade (estat class). Desta forma, pressupóe-se que a utilidade marginal da renda é constante entre o status-quo e a mudança para esta amostra, ou seja, a variável explicativa renda, não entra no modelo.

Após escolhido o modelo, foi realizada uma análise das variáveis. Nota-se na tabela 6 que as variáveis sexo, escolaridade e tempo de permanência não foram significativas a $10 \%$ para explicar a DAP. As variáveis significativas pelo menos a $10 \%$ foram idade, frequência e valor apresentado. Assim, gerou-se o seguinte Modelo Linear na renda:

$$
\operatorname{Pr}(\theta<(0.0083 \text { Idade }+0,133 \text { Freq }+0,120 t))
$$

Onde $\operatorname{Pr}$ corresponde à probabilidade de dizer sim ao pagamento; $\theta \mathrm{a}$ Distribuição do erro amostral, neste caso segue distribuição normal; a idade varia de 18 a 77. A Frequência foi tabulada da seguinte forma: Estipulado o valor (0) para a primeira vez que visita o parque, para quem frequenta até uma vez na semana valor (1), os que visitam uma vez entre quinze e trinta dias valor (2), uma vez a cada dois meses valor (3), uma vez ao ano quatro (4) e todos os dias (5). 


\section{Tabela 6}

\section{Resultado da estimaçáo do Modelo Log-linear na renda (Probit)}

\begin{tabular}{lcccc}
\hline & & & $\begin{array}{c}\text { Número de } \\
\text { observaçóes }\end{array}$ & 520 \\
\cline { 3 - 5 } & & & $\begin{array}{c}\text { LR chi2 }(6) \\
\text { Prob>chi2 }\end{array}$ & 100.22 \\
& & & 0.0000 \\
Log likelihood $=-308.4642$ & & Pseudo R2 & 0.1397 \\
\hline \multicolumn{1}{c}{ Variável } & Coeficiente & Std. Err. & $z$ & $P>(z)$ \\
\hline Idade & -.0083966 & .0043639 & -1.92 & 0.054 \\
Sexo & -.068853 & .1244811 & -0.55 & 0.580 \\
Escolaridade & -.0449604 & .040032 & -1.12 & 0.261 \\
TPermanência & .895691 & .0895691 & 1.42 & 0.156 \\
Frequência & -.1332045 & .0489994 & -2.72 & 0.007 \\
Var2t & -.1205346 & .0163626 & -7.37 & 0.000 \\
Cons & -.0440908 & .3905697 & -0.11 & 0.910 \\
\hline
\end{tabular}

Fonte: elaboração dos autores (2016).

Considerando-se o modelo proposto, a DAP média estimada foi de $\mathrm{R} \$ 8.30$ mensal, valor esse condizente com outras pesquisas como em Gomes da Silva (2003) que estimou o valor de $\mathrm{R} \$ 7.88$ por visitante, para contribuir com a conservação e manutenção do Parque Chico Mendes na cidade de Rio Branco - AC; Castro e Gomes-Castro (2014) encontrou o valor de $\mathrm{R} \$ 5.15$ por visitante para a manutenção de parques no município da cidade de Anápolis - GO. No âmbito internacional, o estudo de Chen e Qi (2017) encontrou valores de DAP entre USD 1.60 a USD 2.00 ( R \$ 5.44 a R \$ 6.80) para o Parque Florestal Nacional de Fuzhou (FNFP), a pesquisa foi feita com 249 visitantes entre o ano de 2015 e 2016. Eles afirmam ter um número considerável de respostas de protesto e que estas podem ter causado viés de seletividade.

O modelo estimado prevê corretamente $73.89 \%$ dos resultados, e a probabilidade de dizer sim ao pagamento da DAP no ponto médio foi de $50.53 \%$, condicionalmente às variáveis explicativas, para tal foi utilizado o valor médio de cada variável explicativa.

Considerando que a populaçáo que visita o parque é de 30,000 pessoas por mês e a DAP média estimada de 8.30 mensal, o valor econômico do local seria de aproximadamente 249,000 ao mês, ou 2,988,000 ao ano. Este valor está próximo à valores encontrados em outros estudos. Segundo, Braz de Sousa e Aroudo-Mota (2006), no Parque Metropolitano do Pituaçu-BA, o número de visitantes dispostos a pagar foi de $63.4 \%$, o valor agregado estimado foi de $\mathrm{R} \$ 2,280,000$ por ano. De acordo com Pepper 
(2005) o valor agregado obtido para o Hartfield Park em Perth-Austrália foi de $\mathrm{R} \$ 3,300,000$ por ano e o percentual de moradores dispostos a pagar foi de $77 \%$.

\section{Conclusóes}

Este trabalho buscou estimar e avaliar o valor econômico do Parque Tia Nair, pois a valoração econômica de parques urbanos, assim como de outros espaços constitui uma ferramenta importante para o planejamento urbano. Por meio das entrevistas necessárias para aplicação do método de valoração contingente também foi possível analisar a percepção dos moradores com relação ao local estudado, assim como perfil da população que o utiliza.

Mediante aplicação do método de valoração contingente, foi possível avaliar a disposiçáo a pagar por parte dos frequentadores e visitantes do Parque Tia Nair visando possibilitar a melhorara, manutenção e conservaçáo do Parque. O perfil socioeconômico dos entrevistados indicou um nível de escolaridade de médio a alto com remuneraçáo entre um e três salários mínimos para os frequentadores do Parque, sendo que, para a maioria dos entrevistados, o maior atrativo da área foi a segurança e a infraestrutura proporcionado pela mesma. Os resultados mostraram que há uma crescente busca pela populaçáo, principalmente aqueles com idade entre 25 a 31 anos, por ambientes seguros e com infraestrutura para a prática de suas atividades de lazer e que beneficiam a saúde.

$\mathrm{O}$ fato de o parque ter funcionamento noturno e a cidade ser carente de ambientes como este, pode ter supervalorizado a disposição a pagar (DAP). De acordo com os resultados, indivíduos mais jovens valorizam mais o meio ambiente, possivelmente pela preocupação com seu futuro e querem ambientes saudáveis e com segurança para praticar suas atividades. Por outro lado, para os indivíduos que não aceitaram pagar, pode se observar uma descrença por parte dos entrevistados no poder público, principalmente diante do cenário de crise política e econômica que o Brasil estava passando no período da aplicação do questionário. Isso pode ter influenciando significativamente o não pagamento da DAP, gerando o viés de "protesto". Muitos afirmavam que a manutenção e conservação do parque seria de competência e de obrigação do poder público, por isso, não aceitariam pagar.

Considerando duas técnicas diferentes, pode-se observar que o valor médio encontrado da DAP da técnica Open-ended R \$9.01 indicou não ser um bom referencial de valor mensal para entrar no Parque diante da análise de outros estudos semelhantes. Pode-se dizer que esta técnica, 
como já verificado em outros trabalhos possui valores muito variados, o que pode aumentar o viés e o valor encontrado não corresponder ao valor real de mercado. A técnica Referendum com Bidding Games apresentou um valor inferior ao do open-ended. O valor inicial proposto do lance foi de $\mathrm{R} \$ 4.00$, e por meio das informaçóes primárias advindas do questionário e do modelo linear na renda estimou o valor $\mathrm{R} \$ 8.30$ mensal para se frequentar o Parque, valor este mais próximo de estudos semelhantes utilizados em outros locais. Isso mostra que a técnica utilizada pode influenciar nos resultados obtidos.

Foi possível observar, durante a aplicação do questionário, que o entrevistado tem preferência por técnicas que estipulem um valor inicial, mesmo que se ofereçam lances maiores depois. Era comum ouvir dúvidas dos entrevistados para se estipular um valor sem nenhuma referência, pois sentiam dificuldades em valorar algo que não se tinha um valor base estipulado. Isso mostra que a técnica Open-ended, embora mais simples do ponto de vista matemático e de modelagem, possui mais dificuldades na aplicabilidade do questionário e pode gerar respostas com alto grau de variabilidade, o que prejudica o resultado obtido, desta forma náo constituindo a técnica mais apropriada para se valorar um bem ambiental.

Cabe salientar que a maioria da população entrevistada aceitaria pagar algum valor para contribuir com a melhoria e manutenção do parque. Este constitui um dos maiores resultados da pesquisa. Mesmo em período de recessão, em que uma parcela considerável da população estava desempregada (20\% dos entrevistados) e revoltada com o governo e a corrupção, os benefícios propiciados pelo parque urbano ainda eram tidos como prioritários e merecedores de investimentos. Dentre os benefícios citados pelos entrevistados, destacam-se: amenizar o stress do dia-a-dia, esquecer um pouco dos problemas, praticar atividades físicas, conhecer e interagir com pessoas, brincar com as crianças.

O valor encontrado de aproximadamente $R \$ 2,988,000$ ao ano, diante de um valor da DAP de $\mathrm{R} \$ 8.30$ mensal e uma população de visitantes de 30,000 indivíduos, é representativo e condiz com outros estudos semelhantes. Utiliza-se o valor econômico, pois ele detém informaçóes mais compreensíveis do ponto de vista de mercado, no entanto, os benefícios advindos de um adequado planejamento urbano e regional que priorize a implantação e conservação de parques arborizados, estruturados e com segurança é superior ao encontrado. Vislumbra-se que o bem-estar e a qualidade de vida da população impactam de forma direta na saúde e indiretamente em outras variáveis como trabalho, educação, taxas de criminalidade, entre outras. Diante desta abordagem, procura-se atrair a atençáo dos tomadores de decisão e da sociedade para a importância de se conservar e ampliar os espaços que possuam estas características. 


\section{Referências}

Abad, Maristela (2002), "Valoração econômica do meio ambiente: o método de valoração contingente no Brasil", dissertação de mestrado em Economia e Gestão Econômica do Meio Ambiente, Universidade de Brasília, Brasília, Brasil.

Alencar-Maymone, Marco Antonio de (2009), "Parques urbanos -origens, conceitos, projetos, legislação e custos de implantação estudo de caso. Parque das naçōes indígenas de Campo Grande-MS”, dissertação de mestrado em Tecnologias Ambientais, Universidade Federal de Mato Grosso do Sul, Campo Grande, Brasil.

Atlas do Desenvolvimento Humano no Brasil (2011), Índice de Desenvolvimento Humano Municipal. Atlas Brasil, Cuiabá, Brasil, $<$ http://www.atlasbrasil.org.br/2013/pt/perfil_m/cuiaba_mt>, 10 de novembro de 2016.

Braz de Sousa, Geneci e José Aroudo-Mota (2006) "Valoração econômica de áreas de recreação: o caso do Parque Metropolitano de Pituaçu, Salvador, BA", Revista de Economia, 32 (1), Universidade Federal do Paraná, Curitiba, Brasil, pp. 37-55.

Cançado-Viana, Juliane Flávia, Lucijane Monteiro de Abreu, José Carlos Junior e Weeberb Requia (2006), "Valoração ambiental do parque ecológico e de uso múltiplo olhos d'água como subsídio à sua concessão", IX Encontro Nacional da ECOECO Políticas Públicas e Perspectiva da Economia Ecológica, del 4 al 8 de outobro, Brasília, Brasil.

Castro, Joana D’arc Bardella e Mário Cesar Gomes-Castro (2014), "Parques municipais em avaliação: uma aplicação do método de valoração contingente para o município de Anápolis/Go", 3º. Colóquio Ibero-Americano: Paisagem cultural, patrimônio e projeto- desafios e perspectivas, Belo Horizonte, del 15 al 17 de setembro, Brasil.

Chen, Bixia e Xinhua Qi (2017), "Protest response and contingent valuation of an urban forest park in Fuzhou City, China", Urban 
Forestry \& Urban Greening, vol. 29, Elsevier, Amsterdam, Holanda, pp. 68-76.

CNS (Conselho Nacional de Saúde) (2016), "Resolução CNS, núm. 510 de 7 de abril de 2016", Resolução dispóe sobre as normas aplicáveis a pesquisas em Ciências Humanas e Sociais, Brasília, Brasil.

Davis, Robert (1963), "The value of outdoor recreation: an economic study of the Maine woods", doctoral dissertation, Harvard University, Cambridge, Estados Unidos da América.

Dias-Ferreira, Adjalme (2005), "Efeitos positivos gerados pelos parques urbanos: o caso do passeio público da cidade do Rio de Janeiro", dissertação de mestrado em Ciência Ambiental, Universidade Federal Fluminense, Rio de Janeiro, Brasil.

Gil, Antônio Carlos (2008), Métodos e Técnicas de Pesquisa Social, 6 ed., Editora Atlas, São Paulo, Brasil.

Gomes da Silva, Rudicleis (2003), "Valoração do parque ambiental 'Chico Mendes', Rio Branco-AC: uma aplicação probabilística do método Referendum com Bidding Games", dissertação de mestrado em Economia Aplicada, Universidade Federal de Viçosa, Viçosa, Brasil.

Gomes-Paixão, Antonino (2011), "A valoração econômica da Lagoa da Princesa: nascente do Rio Paraguai", dissertação de mestrado em Agronegócios e Desenvolvimento Regional, Universidade Federal de Mato Grosso, Cuiabá, Brasil.

Grena-Kliass, Rosa (1993), Parques urbanos de São Paulo, Pini Editora, São Paulo, Brasil.

Haab, Timothy C. e Kenneth E. McConnell (2002), Valuing environmental and natural resources: the econometrics of non-market valuation, Edward Elgar Publishing, Cheltenham, UK, Northampton, MA, Cornwall, Londres.

Hammack, Judd e Gardner Mallard-Brown (1974), Waterfowl and wetlands: toward bioeconomic analysis, John Hopkins University Press, Baltimore, Estados Unidos da América. 
IBGE (Instituto Brasileiro de Geografia e Estatística) (2015), "Cidades", IBGE, Brasília, Brasil. <https://cidades.ibge.gov.br/>, 10 de junho de 2017.

Lerner, Jaime (2010), Acupuntura urbana, 4a ed., Record, Rio de Janeiro, Brasil.

Lopes da Costa, Marcelo Ednan (2016), "Modelos econométricos na avaliação contingente de uma unidade de conservação urbana com utilizaçáo da técnica Delphi e referendo", dissertação de mestrado em Ciências Florestais e Ambientais, Universidade Federal de Mato Grosso, Cuiabá, Brasil.

Maciel da Silva, Luciene de Jesus (2003), “Parques urbanos: a natureza na cidade: uma análise da percepção dos atores urbanos”, dissertação de mestrado em Desenvolvimento Sustentado, Universidade de Brasília-Centro de Desenvolvimento Sustentado, Brasília, Brasil.

Myers, Kelley, George Parsons e Kenneth Train (2017), "Inadequate response to frequency of payments in contingent valuation of environmental goods", em Daniel McFadden e Kenneth Train (eds.), Contingent Valuation of Environmental Goods, Edward Elgar Publishing, Inc., Massachusetts, Estados Unidos da América, pp. 43-57.

Pepper, Coral, Laura McCann e Michael Burton (2005), "Valuation study of urban bushland at Hartfield Park", Ecological Management e Restoration, 6 (3), Ecological Society of Australia e John Wiley and Sons, Forrestfield, Australia, pp. 190-196.

Prefeitura de Cuiabá (2016), "Nota de Esclarecimento-Parque Tia Nair é público e do povo”, Prefeitura de Cuiabá, Cuiabá, Brasil, <http:// www.cuiaba.mt.gov.br/governo-e-comunicacao/nota-de-esclarecimento-parque-tia-nair-e-publico-e-do-povo/12332>, 26 de novembro de 2016.

Rodríguez-Alomá, Patricia (2013), "O espaço público, esse protagonista da cidade”, Arch Daily, Curitiba, Brasil, <http://www.archdaily.com.br/ br/01-162164/o-espaco-publico-esse-protagonista-da-cidade>, 21 de setembro de 2016. 
Sachs, Ignacy (2008), Caminhos para o desenvolvimento sustentável, Garamond, Rio de Janeiro, Brasil.

Se-Young, Park e Lee Won-Seok (2017), "Valuation of the Jidong Mural Art alley using the contingent valuation method: an application of nostalgia", Journal of Tourism Sciences, vol. 41, The Toursim Scicenes Society of Korea, Seoul, Korea, pp. 45-62.

Seroa da Motta, Ronaldo (1997), Manual para valoração econômica de recursos ambientais, Coordenação de Estudos do Meio Ambiente do Instituto de Pesquisa Econômica Aplicada (CEMA/IPEA) e da Coordenação Geral de Diversidade Biológica do Ministério do Meio Ambiente, dos Recursos Hídricos e da Amazônia Legal, Brasília, Brasil.

Silva, Jorge Luiz da, Mirella Riva, Alencar Garcia Bacarji e Patrícia Costa Rodrigues (2012), "Valoração Ambiental de Áreas de Preservação Permanente (APP's): um estudo de caso no bairro jardim universitário, Cuiabá, Mato Grosso", III Congresso Brasileiro de Gestão Ambiental, del 19 al 22 de novembro, Goiânia, Brasil.

Tafuri, Antonio Carlos (2008), "Valoração ambiental do Parque Estadual do Itacolomi, Ouro Preto, Minas Gerais", dissertação de mestrado em Saneamento, Meio Ambiente e Recursos Hídricos, Universidade Federal de Minas Gerais, Belo Horizonte, Brasil.

Villalba-González, Moisés (2004), "Valor de visitação do Parque 'Phillipe Westin Cabral de Vasconcelos' da Escola Superior de Agricultura 'Luiz de Queiroz' (ESALQ) da Universidade de São Paulo (USP)", dissertação de mestrado, Piracicaba, Escola Superior de Agricultura "Luiz de Queiroz", Universidade de São Paulo, São Paulo, Brasil.

Zwilling-Stampe, Mariane, Daniela Goya-Tocchetto e Stefano Florissi (2008), "Utilizando a metodologia de valoração contingente para estimar os benefícios gerados aos usuários pela Feira do Livro de Porto Alegre", Associação Nacional dos Centros de Pós-graduação em Economia, Porto Alegre, Brasil, pp. 1-19.

Recibido: 29 de septiembre de 2017. Reenviado: 22 de noviembre de 2017. Aceptado: 11 de enero de 2018. 
Fabiana Loeblein. Especialista em Sustentabilidade pela Universidade Federal de Mato Grosso. Possui graduação em Ciências Biológicas pelo Centro Universitário de Várzea Grande. Atualmente é professora da Secretaria de Estado de Educação do Estado do Mato Grosso (Brasil). Linhas de pesquisa em Métodos de Valoração Contingente, Ensino de Ciências e Biologia, Estrutura e Funcionamento da Educação Básica, Processo de Ensino e Aprendizagem.

Maria Daniele de Jesus-Teixeira. Doutora em Economia pela Universidade de Brasília, Mestre em Agronegócios e Desenvolvimento Regional pela Universidade Federal de Mato Grosso, Especialista em Economia e Finanças pela Faculdade de Sinop, possui graduação em Ciências Econômicas pela Universidade Estadual de Mato Grosso. Atualmente é economista da Universidade Federal de Mato Grosso e professora do curso de Especialização em Sustentabilidade do departamento de Economia da UFMT. Possui linhas de pesquisa na área de Economia, com ênfase em Agropecuária, Meio-Ambiente, Desenvolvimento Regional, Macroeconomia, Macroeconomia Ambiental, Economia Ambiental, Economia Ecológica e Métodos Quantitativos. Entre as últimas publicaçóes destacam-se: "Bem-estar Fundamental e Econômico: Uma análise crítica do PIB e dos Indicadores de Sustentabilidade", Revista Gestão e Sustentabilidade Ambiental, 6 (1), UNISOL Santa Catarina, Brasil, pp. 4-40 (2017); "Análise Intersetorial e Espacial da cadeia produtiva da madeira e móveis na economia de Mato Grosso: Uma contribuição para identificação de APLs", Revista Brasileira de Gestão e Desenvolvimento Regional, 13 (2), Universidade de Taubaté, SP, Brasil, pp. 103-128 (2017) e "Investimentos para mitigação da emissão de GEE no Brasil: Perspectivas da macroeconomia ambiental", tese de doutorado, Universidade de Brasília, Brasília, Brasil, 2017. 